\title{
The institutional learning curve is associated with survival outcomes of robotic radical hysterectomy for early-stage cervical cancer-a retrospective study
}

\author{
Kyung Jin Eoh ${ }^{1,2}$, Jung-Yun Lee², Eun Ji Nam², Sunghoon Kim², Sang Wun Kim² and Young Tae Kim² (D)
}

\begin{abstract}
Background: Despite recent advances in diagnosis and treatment, cervical cancer continues to be a significant health problem worldwide. Whereas robot-assisted surgery has advantages over the abdominal approach, and minimally invasive techniques are being used increasingly, these may be associated with a higher recurrence rate and lower overall survival than the abdominal approach. The objective of this study was to compare the surgical and survival outcomes between abdominal radical hysterectomy (ARH) and robotic radical hysterectomy (RRH).
\end{abstract}

Methods: A retrospective cohort of patients undergoing radical hysterectomy for cervical cancer from 2006 to 2018 was identified. Patients with stage IA to IB cervical cancer were included and grouped: ARH vs. RRH. The RRH group was further divided into two groups based on the year of enrollment: RRH1 (2006-2012) and RRH2 (2013-2018). Tumor characteristics, recurrence rate, progression-free survival (PFS), and overall survival (OS) were compared between the groups. P-values $<0.05$ (two-sided) were considered statistically significant.

Results: A total of 310 patients were identified: 142 and 168 underwent $\mathrm{ARH}$ and $\mathrm{RRH}$, respectively. $\mathrm{RRH} 1$ and $\mathrm{RRH} 2$ had 77 and 91 patients, respectively. Interestingly, RRH2 was more likely to have a larger tumor size (1.7 \pm 1.4 vs. $2.0 \pm 1.1$ vs. $2.4 \pm 1.7 \mathrm{~cm}, P=0.014)$ and higher stage $(P<0.001)$ than RRH1. However, RRH2 showed significantly favorable PFS in contrast to RRH1. There was no difference between ARH and RRH2 in PFS $(P=0.629)$, whereas overall, the RRH group showed significantly shorter PFS than the ARH group. In the multivariate analysis, the institutional learning curve represented by the operation year was one of the significant predictors for PFS (hazard ratio $[H R] 0.065, P=0.0162)$, along with tumor size (HR 5.651, $P=0.0241)$.

Conclusions: The institutional learning curve, represented by the operation year, is one of the most significant factors associated with outcomes of RRH for early-stage cervical cancer.

Keywords: Learning curve, Hysterectomy, Cervical cancer

\footnotetext{
* Correspondence: ytkchoi@yuhs.ac

${ }^{2}$ Division of Gynecologic Oncology, Department of Obstetrics and Gynecology, Severance Hospital, Institute of Women's Life Medical Science,

Yonsei University College of Medicine, 50-1 Yonsei-ro, Seodaemun-gu, Seoul 03722, South Korea

Full list of author information is available at the end of the article
}

(c) The Author(s). 2020 Open Access This article is licensed under a Creative Commons Attribution 4.0 International License, which permits use, sharing, adaptation, distribution and reproduction in any medium or format, as long as you give appropriate credit to the original author(s) and the source, provide a link to the Creative Commons licence, and indicate if changes were made. The images or other third party material in this article are included in the article's Creative Commons licence, unless indicated otherwise in a credit line to the material. If material is not included in the article's Creative Commons licence and your intended use is not permitted by statutory regulation or exceeds the permitted use, you will need to obtain permission directly from the copyright holder. To view a copy of this licence, visit http://creativecommons.org/licenses/by/4.0/ The Creative Commons Public Domain Dedication waiver (http://creativecommons.org/publicdomain/zero/1.0/) applies to the data made available in this article, unless otherwise stated in a credit line to the data. 


\section{Background}

Although the recent widespread implementation of screening and prevention has decreased the incidence and mortality rates of cervical cancer, it continues to be a major public health problem [1]. Patients with early-stage cervical cancer are universally regarded as being ideal candidates for radical hysterectomy and pelvic lymph node (LN) dissection [2].

Conventionally, only the abdominal approach has been performed, but as technology related to minimally invasive surgery (MIS) continues to develop, the mainstream approach has been shifting to laparoscopic and robotassisted surgery in radical hysterectomy [3, 4]. Further, previous studies have shown that the robot-assisted approach has several advantages over the abdominal approach, including decreased blood loss, higher counts of harvested LNs, fewer major complications, and shorter hospital stay [5-12].

However, recently released data from the Laparoscopic Approach to Cervical Cancer (LACC) trial (NCT00614211) indicated a higher recurrence rate and lower overall survival (OS) in patients with cervical cancer who were surgically treated with MIS than in those treated via the abdominal approach [13]. However, the unfavorable outcome of the MIS arm in the LACC trial could be a result of the surgical technique or negligence of the surgeon, rather than due to the MIS itself.

The aim of our study was to compare patient features, tumor characteristics, and survival outcomes in a retrospective cohort of patients who underwent abdominal radical hysterectomy (ARH) versus robotic radical hysterectomy (RRH) for cervical cancer at a tertiary referral institution and to evaluate factors that could impact the oncologic outcomes of RRH.

\section{Methods}

Patients

A retrospective cohort of patients who underwent RRH or ARH for cervical cancer between 2006 and 2018 at Yonsei Cancer Center, Severance Hospital was identified. Clinical data, including patient demographics, tumor characteristics, and clinical outcomes, were abstracted from the electronic medical records. All patients with a preoperative diagnosis of cervical cancer of squamous cell, adenocarcinoma, or adenosquamous histologies with a Federation of Gynecology and Obstetrics (FIGO) stage (prior to the revision in 2018) of less than II were included [14]. Those who received neoadjuvant chemotherapy prior to the surgery, whose FIGO stage was II, or who had histologies other than squamous cell, adenocarcinoma, or adenosquamous were excluded. Progression-free survival (PFS) was defined as the time interval between surgery and the first evidence of any recurrence or last follow-up. OS was described as the duration of time from the date of diagnosis to the date of death or last follow-up. The study was approved by the Institutional Review Board at Yonsei University College of Medicine.

\section{Surgical techniques}

The type of surgical approach was determined after a discussion with each patient about the risks and benefits of both options. All patients in this cohort underwent type B-to-C radical hysterectomy, as described by Querleu and Morrow [15]. A systematic pelvic lymphadenectomy was performed, which included removal of the internal iliac nodes, external iliac nodes, obturator nodes, and common iliac nodes. Since the introduction of sentinel LN (SLN) biopsy in surgery for cervical

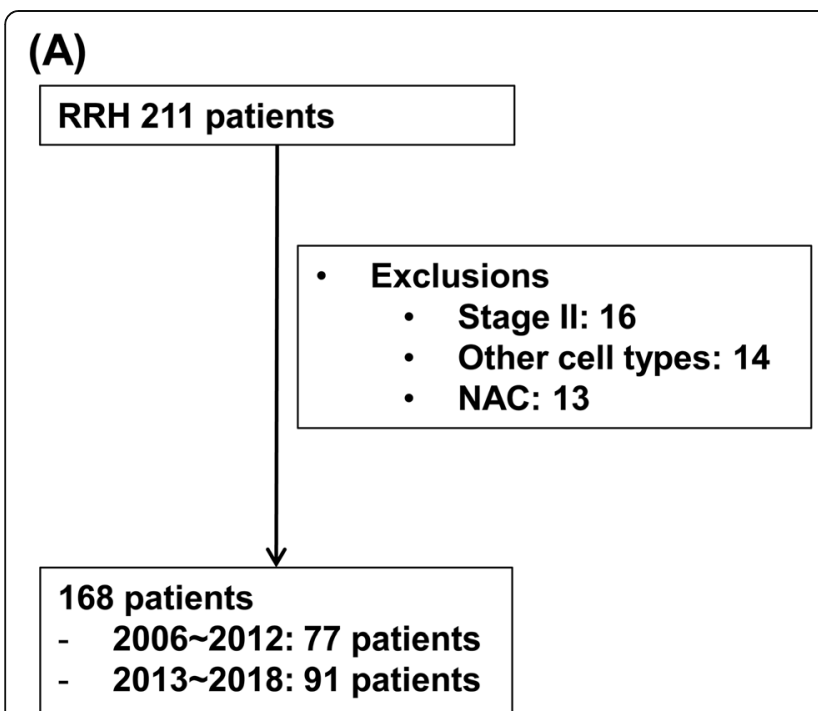

(B)

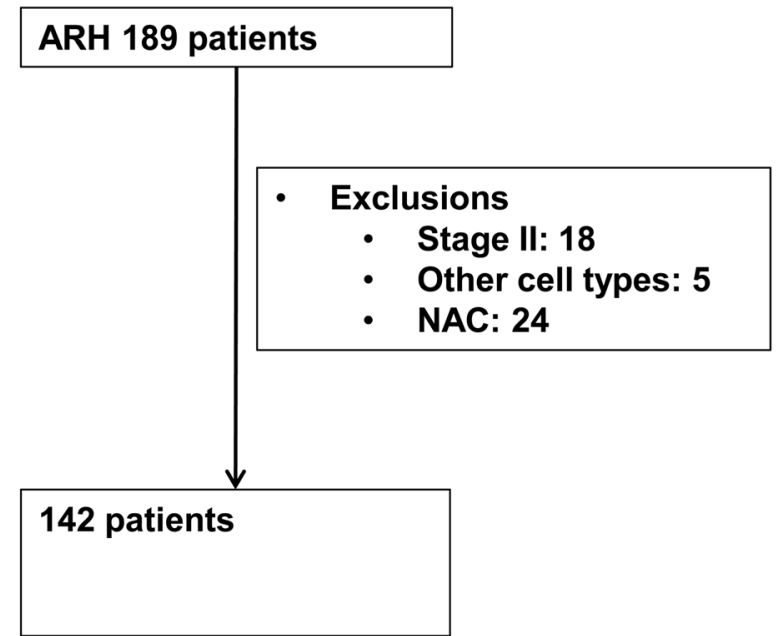

Fig. 1 Flowchart of patient selection. Selection of patients who underwent RRH (a) and ARH (b). RRH, robotic radical hysterectomy; ARH, abdominal radical hysterectomy; NAC, neoadjuvant chemotherapy 
Table 1 Patient characteristics

\begin{tabular}{|c|c|c|c|c|}
\hline & ARH $(N=142)$ & RRH1 ('06-'12) $(N=77)$ & RRH2 ('13-'18) $(N=91)$ & $P$ \\
\hline Age & $49.7 \pm 11.3$ & $46.7 \pm 10.3$ & $45.3 \pm 9.8$ & 0.002 \\
\hline BMI & $23.5 \pm 3.4$ & $22.8 \pm 4.0$ & $23.4 \pm 3.2$ & 0.761 \\
\hline Stage & & & & $<0.001$ \\
\hline $1 \mathrm{~A} 1$ & $14(9.9 \%)$ & $12(15.6 \%)$ & $12(13.2 \%)$ & \\
\hline $1 \mathrm{~A} 2$ & $10(7.0 \%)$ & $2(2.6 \%)$ & $1(1.1 \%)$ & \\
\hline 1B1 & $90(63.4 \%)$ & $63(81.8 \%)$ & $68(74.7 \%)$ & \\
\hline 1B2 & $28(19.7 \%)$ & 0 & $10(11.0 \%)$ & \\
\hline Cell type & & & & 0.157 \\
\hline SCC & $106(74.6 \%)$ & $58(75.3 \%)$ & $60(65.9 \%)$ & \\
\hline$A C$ & $32(22.5 \%)$ & $18(23.4 \%)$ & $31(34.1 \%)$ & \\
\hline AS & $4(2.8 \%)$ & $1(1.3 \%)$ & 0 & \\
\hline
\end{tabular}

ARH Abdominal radical hysterectomy, RRH Robotic radical hysterectomy, BMI Body mass index, SCC Squamous cell carcinoma, AC Adenocarcinoma, AS Adenosquamous

cancer, it has been performed in our institution at the discretion of the surgeon [16]. All the radical hysterectomies were performed by the same board-certified gynecologic oncologists at a single tertiary referral hospital and assisted by gynecologic oncology fellows.

\section{Statistical analysis}

Differences in patient demographics and tumor characteristics were compared using the Student's $t$ test and Chi-square test where appropriate. Cox proportional hazards regression analysis was used to estimate hazard ratios (HRs) and 95\% confidence intervals (CIs). The Kaplan-Meier analysis was used to estimate the change in survival. $P$-values $<0.05$ (two-sided) were considered statistically significant. Numerical data are presented as number (\%) or the median \pm standard deviation. Statistical analyses were performed using SPSS version 25.0 for Windows (IBM, Chicago, IL, USA) and R Statistical Software version 3.6.1 (Foundation for Statistical Computing, Vienna, Austria).

\section{Results}

Figure 1 shows a flowchart of the patient selection process. In total, 310 patients were identified, of whom 142 underwent ARH and 168 underwent RRH. Patients who underwent RRH between 2006 and 2012 were classified as RRH1, and patients who underwent RRH between 2013 and 2018 were classified as RRH2. RRH1 and RRH2 consisted of 77 and 91 patients, respectively.

Patients in RRH2 were more likely to have a higher stage, compared with ARH or RRH1 $(P<0.001)$. The ARH group was significantly younger than the two other groups $(P=0.002)$. Body mass index and cell type were not significantly different among the three groups (Table 1). Table 2 presents the outcomes of surgery and postoperative adjuvant treatments. The ARH group showed deeper invasiveness $(P<0.001)$ and more lymphovascular space invasion (LVSI; $P<0.001$ ). In RRH2, a significantly reduced number of harvested LNs was observed, which is expected to be the result of the SLN biopsy introduced in our hospital in 2012. Additionally,

Table 2 Pathological results and postoperative treatment

\begin{tabular}{|c|c|c|c|c|}
\hline & $\mathrm{ARH}(\mathrm{N}=155)$ & RRH1 ('06-'12) $(\mathrm{N}=77)$ & RRH2 ('13-'18) ( $N=91)$ & $P$ \\
\hline Depth of invasion & $0.8 \pm 0.5$ & $0.6 \pm 0.6$ & $0.5 \pm 0.5$ & $<0.001$ \\
\hline LVSI & 55 (50.5\%) & $21(27.3 \%)$ & 19 (20.9\%) & $<0.001$ \\
\hline Harvested pelvic LNs & $19.7 \pm 9.8$ & $16.6 \pm 9.2$ & $9.6 \pm 9.0$ & $<0.001$ \\
\hline LN metastasis & $16(11.3 \%)$ & $4(5.2 \%)$ & $9(9.9 \%)$ & 0.188 \\
\hline Tumor size & $1.7 \pm 1.4$ & $2.0 \pm 1.1$ & $2.4 \pm 1.7$ & 0.014 \\
\hline Postoperative treatment & & & & 0.001 \\
\hline RT & $28(19.7 \%)$ & $5(6.5 \%)$ & $4(4.4 \%)$ & \\
\hline POAC & $9(6.3 \%)$ & $6(7.8 \%)$ & $1(1.1 \%)$ & \\
\hline CCRT & $9(6.3 \%)$ & 7 (9.1\%) & $11(12.1 \%)$ & \\
\hline
\end{tabular}

ARH Abdominal radical hysterectomy, RRH Robotic radical hysterectomy, LVSI Lymphovascular space invasion, LN Lymph node, RT Radiotherapy, POAC Postoperative adjuvant chemotherapy, CCRT Concurrent chemoradiotherapy 
RRH2 was more likely to have a larger tumor size than the ARH group $(2.4 \pm 1.7$ vs. $1.7 \pm 1.4 \mathrm{~cm}, P=0.014)$.

In the multivariate analysis, the institutional learning curve, represented by the year of operation, was one of the significant predictors for PFS (HR 0.065, $P=0.0162$ ), along with tumor size (HR 5.651, $P=0.0241$ ) (Table 3). Moreover, LVSI and postoperative treatments were also

Table 3 Multivariate analysis of various factors correlated with progression-free survival

\begin{tabular}{|c|c|c|c|}
\hline & \multirow{3}{*}{$\begin{array}{l}\text { No. of } \\
\text { patients }\end{array}$} & \multicolumn{2}{|l|}{ PFS } \\
\hline & & \multicolumn{2}{|l|}{ Multivariate analysis } \\
\hline & & HR (95\% Cl) & $P$ \\
\hline Age, years (continuous) & 168 & 1.025 (0.956-1.099) & 0.4894 \\
\hline \multicolumn{4}{|l|}{ LC } \\
\hline $2006 \sim 2012$ & 77 & 1 (Reference) & \\
\hline 2013 2018 & 91 & $0.065(0.007-0.603)$ & $0.0162^{*}$ \\
\hline \multicolumn{4}{|l|}{ BMI } \\
\hline$<25$ & 130 & 1 (Reference) & \\
\hline$\geq 25$ & 38 & $0.243(0.025-2.404)$ & 0.2264 \\
\hline \multicolumn{4}{|l|}{ Stage } \\
\hline IB1, IB2 & 141 & 1 (Reference) & \\
\hline$|A 1| A 2$, & 27 & $0.638(0.092-4.446)$ & 0.6502 \\
\hline \multicolumn{4}{|l|}{ Histology } \\
\hline SCC & 118 & 1 (Reference) & \\
\hline$A C \& A S$ & 50 & $1.367(0.375-4.986)$ & 0.6357 \\
\hline \multicolumn{4}{|l|}{ Invasiveness } \\
\hline$<0.3 \mathrm{~cm}$ & 97 & 1 (Reference) & \\
\hline$\geq 0.3 \mathrm{~cm}$ & 71 & $1.139(0.297-4.363)$ & 0.8493 \\
\hline \multicolumn{4}{|l|}{ LVSI } \\
\hline No & 128 & 1 (Reference) & \\
\hline Yes & 40 & $4.590(0.973-21.659)$ & 0.0543 \\
\hline
\end{tabular}

No. of harvested LNS

$\begin{array}{llll}<20 & 129 & 1 \text { (Reference) } & \\ \geq 20 & 39 & 0.325(0.068-1.557) & 0.1597 \\ \text { Metastatic LNs } & & & \\ \text { No } & 155 & 1 \text { (Reference) } & \\ \text { Yes } & 13 & 2.609(0.424-16.041) & 0.3006\end{array}$

Tumor size

$<2 \mathrm{~cm} \quad 125 \quad 1$ (Reference)

$\geq 2 \mathrm{~cm} \quad 43 \quad 5.651(1.255-25.448) \quad 0.0241^{*}$

Postoperative treatment

$\begin{array}{llll}\text { Yes } & 34 & 1 \text { (Reference) } & 0.0755\end{array}$

No $\quad 134 \quad 0.185(0.029-1.189)$

PFS Progression-free survival, $H R$ Hazard ratio, $C l$ Confidential interval, $L C$ Learning curve, BMI Body mass index, SCC Squamous cell carcinoma, AC Adenocarcinoma, AS Adenosquamous, LVSI Lymphovascular space invasion, $L N$ Lymph node; ${ }^{*}, P<0.05$ observed to be possible predictors of PFS but did not reach statistical significance.

PFS was significantly different between the ARH group and the overall RRH group $(P=0.002)$, but there was no difference between the ARH group and RRH2 $(P=0.629$; Fig. 2a, b). OS did not differ significantly between ARH and $\mathrm{RRH}$, and there was no significant difference among ARH, RRH1, and RRH2 (Fig. 2c, d).

\section{Discussion}

In this study, we compared the surgical outcomes of $\mathrm{ARH}$ and RRH for cervical cancer. In particular, RRH was analyzed by dividing the cohort according to the year of surgery into the first half (RRH1) and the latter half (RRH2). Interestingly, classification according to the year of performance, which is thought to reflect the institutional learning curve, was found to be a significant PFS predictor along with known factors such as tumor size.

Previous retrospective studies have indicated that there is no survival difference between robot-assisted and abdominal approaches, which is consistent with our results [17-21]. In addition, even when stratified by tumor size, oncologic outcomes were not significantly different between laparoscopic and abdominal approaches, which may emphasize the importance of the learning curve over the mode of surgery itself $[22,23]$. In this study, by changing the viewpoint, a comparative analysis was performed using the year of surgery to reflect the learning curve of the institution as an independent factor, which was shown to be the most significant predicting factor for oncologic prognosis.

The results of the LACC trial, a multi-center randomized phase III trial evaluating the long-term survival of women who underwent minimally invasive radical hysterectomy vs. ARH, were presented at the 2018 Society of Gynecologic Oncology (SGO) annual meeting [13]. This study included patients with stages IA1 with LVSI, IA2, and IB1 disease and randomized 631 patients to radical hysterectomy using MIS or abdominal approaches. The LACC trial was indecisive with respect to its primary objective of disease-free survival as the $\mathrm{CI}$ crossed the predetermined noninferiority margin of -7.2 percentage points for MIS (difference, - 10.6 percentage points; $95 \% \mathrm{CI}-16.4$ to $-4.7, P=0.87$ for noninferiority). However, the secondary endpoints of disease-free survival and OS favored the open surgery group. The MIS RH surgery group showed a significantly lower 3year disease-free survival and OS rate than the open $\mathrm{RH}$ surgery group (3-year rate, 91.2\% vs. 97.1\%; HR for disease recurrence or death from cervical cancer, 3.74; $95 \%$ CI, 1.63 to 8.58 ). These unexpected results have already led to a change in practice patterns at many institutions, 


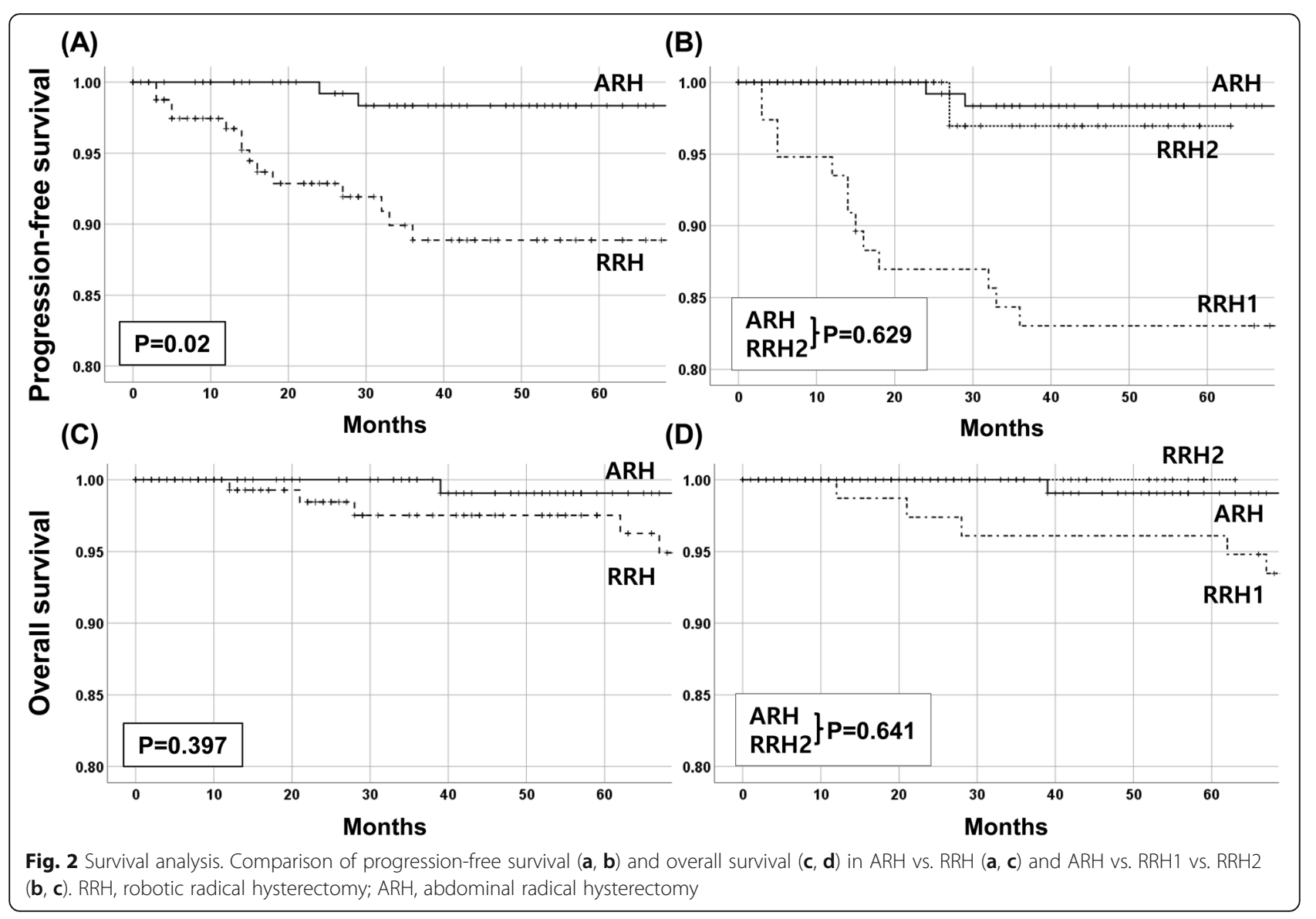

which now have completely terminated or significantly reduced the application of MIS for cervical cancer based on the results of this trial.

In addition, the results of the LACC trial were consistent with those of a retrospective analysis using the Surveillance, Epidemiology, and End Results data of the National Cancer Institute in the USA, which argues that the introduction of MIS was associated with an increased mortality rate due to cervical cancer [24]. In the analysis, MIS was associated with an increased probability of mortality within 4 years compared to laparotomy $(9.1 \%$ vs. $5.3 \%)$. Nonetheless, for patients who had tumors $<2 \mathrm{~cm}$, the HR for death was statistically similar between the two surgical approaches in the subgroup analysis. Other retrospective studies concluded that MIS was associated with decreased survival in women who had tumors $\geq 2 \mathrm{~cm}[25,26]$.

Certain points in the LACC trial, however, have faced criticism. The LACC trial design included surgeons who could submit data from only 10 MIS cases and 2 unedited videos, to exclude the contributing centers' learning curve. However, many gynecologic oncologists suspect that this could not sufficiently support evidence that properly trained surgeons contributed in the MIS arm [27]. Also, we should focus on the result that only 7 recurrences $(2.2 \%)$ were observed in the 312 women in the open surgery arm, which is an extremely low rate of recurrence comparing with previous reports, whereas 27 $(8.4 \%)$ recurrences were noted in the MIS arm, which is comparative to the data reported in previous studies [18, $19,23,28,29]$. This observation suggested that the surgeons who already had overcome the learning curve for MIS; therefore, adopting the MIS approach for cervical cancer as the first option might have been excluded in the LACC trial at the beginning. Moreover, despite including a combination of both conventional laparoscopy and robotic surgery in the MIS arm, the enrolment was heavily skewed toward laparoscopy, and only $15.6 \%(N=$ 45) of women had undergone robotic hysterectomy. Additionally, a substantial proportion of data was missing, with unknown grade $(29 \%)$ or depth of invasion (33\%). Therefore, a well-controlled study that addresses all the above-mentioned concerns is required.

The strengths of this study were that it was conducted at a single tertiary referral institution performing highvolume robot-assisted surgery for cervical cancer and that it compared robotic surgery alone with ARH. Additionally, the characteristics of the included patient population were similar to those of patients included in the LACC trial. Thus, the concerns raised by the 
relatively small number of RRHs in the LACC trial can be addressed. However, there are several limitations related to the retrospective design of this study, including the potential for selection bias, unmeasured confounders, and missing data that may have affected data analysis.

\section{Conclusions}

Our study found that institutional experience with robotic surgery, represented by the operation year, is one of the most significant factors associated with RRH outcomes for early-stage cervical cancer. We should not discard all the benefits of robot-assisted laparoscopy by doing away with the minimally invasive approach for cervical cancer. Before the well-controlled trial is carried out, the mode of surgery should be determined according to each surgeon's proficiency. Surgeons are recommended to counsel their patients and decide on the mode of surgery based on the oncologic outcomes of the previous institutional patients.

\section{Abbreviations}

AC: Adenocarcinoma; ARH: Abdominal radical hysterectomy; AS: Adenosquamous; BMI: Body mass index; CCRT: Concurrent chemoradiotherapy; LN: Lymph node; LVSI: Lymphovascular space invasion; POAC: Postoperative adjuvant chemotherapy; RRH: Robotic radical hysterectomy; RT: Radiotherapy; SCC: Squamous cell carcinoma

\section{Acknowledgements}

We would like to acknowledge Editage for professional English language editing services.

\section{Authors' contributions}

KJE and YTK developed the concept and design of the study. KJE, JYL, EJN, SK, and SWK formulated the methods. KJE and YTK analyzed the data by conducting the statistical and computational analyses and biostatistics. KJE, JYL, EJN, SK, SWK, and YTK wrote, reviewed, and/or revised the manuscript. YTK supervised the study. The authors read and approved the final manuscript.

\section{Funding}

None.

\section{Availability of data and materials}

The datasets used and/or analyzed during the current study are available from the corresponding author on reasonable request.

\section{Ethics approval and consent to participate}

This retrospective study was approved by the Institutional Review Board at Yonsei University College of Medicine.

\section{Consent for publication}

Not applicable.

\section{Competing interests}

The authors declare that they have no competing interests.

\section{Author details}

${ }^{1}$ Department of Obstetrics and Gynecology, Yonsei University College of Medicine, Yongin Severance Hospital, Yongin, Gyeonggi-do 446-916, South Korea. ${ }^{2}$ Division of Gynecologic Oncology, Department of Obstetrics and Gynecology, Severance Hospital, Institute of Women's Life Medical Science, Yonsei University College of Medicine, 50-1 Yonsei-ro, Seodaemun-gu, Seoul 03722, South Korea.
Received: 1 November 2019 Accepted: 20 February 2020

Published online: 24 February 2020

\section{References}

1. Siegel RL, Miller KD, Jemal A. Cancer statistics, 2018. CA Cancer J Clin. 2018; 68(1):7-30.

2. Bansal N, Herzog TJ, Shaw RE, Burke WM, Deutsch I, Wright JD. Primary therapy for early-stage cervical cancer: radical hysterectomy vs radiation. Am J Obstet Gynecol. 2009;201:485.e1-9.

3. Koh W, Abu-Rustum N, Bean S. NCCN Clinical Practice Guidelines in Oncology (NCCN Guidelines ${ }^{\oplus}$ ). Cervical Cancer Version 1; 2018.

4. Yim GW, Kim SW, Nam EJ, Kim YT. Role of robot-assisted surgery in cervical cancer. Int J Gynecol Cancer. 2011;21(1):173-81.

5. Shafer A, Boggess JF. Robotic-assisted endometrial cancer staging and radical hysterectomy with the da Vinci surgical system. Gynecol Oncol. 2008;111(2 Suppl):S18-23.

6. Paley PJ, Veljovich DS, Shah CA, Everett EN, Bondurant AE, Drescher CW, et al. Surgical outcomes in gynecologic oncology in the era of robotics: analysis of first 1000 cases. Am J Obstetr Gynecol. 2011;204(6):551.e551-9.

7. Yim GW, Kim YT. Robotic surgery in gynecologic cancer. Curr Opinion Obstetr Gynecol. 2012;24(1):14-23.

8. Holloway RW, Ahmad S. Robotic-assisted surgery in the management of endometrial cancer. J Obstet Gynaecol Res. 2012;38(1):1-8.

9. Walker JL, Piedmonte MR, Spirtos NM, Eisenkop SM, Schlaerth JB, Mannel RS, et al. Laparoscopy compared with laparotomy for comprehensive surgical staging of uterine cancer: gynecologic oncology group study LAP2. J Clin Oncol. 2009;27(32):5331-6.

10. Brudie LA, Backes FJ, Ahmad S, Zhu X, Finkler NJ, Bigsby GE 4th, et al. Analysis of disease recurrence and survival for women with uterine malignancies undergoing robotic surgery. Gynecol Oncol. 2013;128(2):309-15.

11. Veljovich DS, Paley PJ, Drescher CW, Everett EN, Shah C, Peters WA 3rd. Robotic surgery in gynecologic oncology: program initiation and outcomes after the first year with comparison with laparotomy for endometrial cancer staging. Am J Obstetr Gynecol. 2008;198(6):679.e671-9 discussion 679.e679610.

12. Yim GW, Kim SW, Nam EJ, Kim S, Kim YT. Perioperative complications of robot-assisted laparoscopic surgery using three robotic arms at a single institution. Yonsei Med J. 2015;56(2):474-81.

13. Ramirez PT, Frumovitz M, Pareja R, Lopez A, Vieira M, Ribeiro R, et al. Minimally invasive versus abdominal radical hysterectomy for cervical Cancer. N Engl J Med. 2018;379(20):1895-904.

14. Pecorelli S. Revised FIGO staging for carcinoma of the vulva, cervix, and endometrium. Int J Gynaecol Obstetr. 2009;105(2):103-4.

15. Querleu D, Morrow CP. Classification of radical hysterectomy. The Lancet Oncology. 2008;9(3):297-303

16. Lecuru F, Mathevet P, Querleu D, Leblanc E, Morice P, Darai E, et al. Bilateral negative sentinel nodes accurately predict absence of lymph node metastasis in early cervical cancer: results of the SENTICOL study. J Clinical Oncol. 2011;29(13):1686-91.

17. Mendivil AA, Rettenmaier MA, Abaid LN, Brown JV 3rd, Micha JP, Lopez KL, et al. Survival rate comparisons amongst cervical cancer patients treated with an open, robotic-assisted or laparoscopic radical hysterectomy: a five year experience. Surg Oncol. 2016;25(1):66-71.

18. Shah CA, Beck T, Liao JB, Giannakopoulos NV, Veljovich D, Paley P. Surgical and oncologic outcomes after robotic radical hysterectomy as compared to open radical hysterectomy in the treatment of early cervical cancer. J Gynecol Oncol. 2017;28(6):e82.

19. Sert BM, Boggess JF, Ahmad S, Jackson AL, Stavitzski NM, Dahl AA, et al. Robot-assisted versus open radical hysterectomy: a multi-institutional experience for early-stage cervical cancer. Eur J Surg Oncology. 2016;42(4): $513-22$

20. Cantrell LA, Mendivil A, Gehrig PA, Boggess JF. Survival outcomes for women undergoing type III robotic radical hysterectomy for cervical cancer: a 3-year experience. Gynecol Oncol. 2010;117(2):260-5.

21. Doo DW, Kirkland CT, Griswold LH, McGwin G, Huh WK, Leath CA 3rd, et al. Comparative outcomes between robotic and abdominal radical hysterectomy for IB1 cervical cancer: results from a single high volume institution. Gynecol Oncol. 2019;153(2):242-7.

22. Nam JH, Park JY, Kim DY, Kim JH, Kim YM, Kim YT. Laparoscopic versus open radical hysterectomy in early-stage cervical cancer: long-term survival outcomes in a matched cohort study. Ann Oncol. 2012;23(4):903-11. 
23. Wang $Y Z$, Deng $L, X u H C$, Zhang Y, Liang ZQ. Laparoscopy versus laparotomy for the management of early stage cervical cancer. BMC Cancer. 2015;15:928.

24. Melamed A, Margul DJ, Chen L, Keating NL, Del Carmen MG, Yang J, et al. Survival after minimally invasive radical hysterectomy for early-stage cervical Cancer. N Engl J Med. 2018;379(20):1905-14.

25. Margul DJ, Yang J, Seagle BL, Kocherginsky M, Shahabi S. Outcomes and costs of open, robotic, and laparoscopic radical hysterectomy for stage IB1 cervical cancer. J Clin Oncol. 2018;36(15_suppl):5502.

26. Kim SI, Cho JH, Seol A, Kim YI, Lee M, Kim HS, et al. Comparison of survival outcomes between minimally invasive surgery and conventional open surgery for radical hysterectomy as primary treatment in patients with stage IB1-IIA2 cervical cancer. Gynecol Oncol. 2019;153(1):3-12.

27. Yim GW, Kim SW, Nam EJ, Kim S, Kim YT. Learning curve analysis of robotassisted radical hysterectomy for cervical cancer: initial experience at a single institution. J Gynecol Oncol. 2013;24(4):303-12.

28. Zanagnolo V, Minig L, Rollo D, Tomaselli T, Aletti G, Bocciolone L, et al. Clinical and oncologic outcomes of robotic versus abdominal radical hysterectomy for women with cervical Cancer: experience at a referral Cancer center. Int J Gynecol Cancer. 2016;26(3):568-74.

29. Wallin E, Floter Radestad A, Falconer H. Introduction of robot-assisted radical hysterectomy for early stage cervical cancer: impact on complications, costs and oncologic outcome. Acta Obstet Gynecol Scand. 2017;96(5):536-42

\section{Publisher's Note}

Springer Nature remains neutral with regard to jurisdictional claims in published maps and institutional affiliations.

Ready to submit your research? Choose BMC and benefit from:

- fast, convenient online submission

- thorough peer review by experienced researchers in your field

- rapid publication on acceptance

- support for research data, including large and complex data types

- gold Open Access which fosters wider collaboration and increased citations

- maximum visibility for your research: over $100 \mathrm{M}$ website views per year

At $\mathrm{BMC}$, research is always in progress.

Learn more biomedcentral.com/submissions 